\title{
Diálogo, conflito e movimento identitário no encontro de culturas: uma análise do filme Bagdá Café
}

[Dialogue and conflict in the meeting of two cultures: an analysis of the movie Bagdá Café]

\author{
Elaine C. Roschel Nunes ${ }^{1}$ \\ Franziska Lorke ${ }^{2}$ \\ Henrique Janzen ${ }^{3}$
}

\begin{abstract}
In this article we present an analysis of the main characters in the film Bagdad Café focusing on dialogical processes and cultural conflicts which influence the identity formation and decentering of these characters. The main objective of this paper is to analyze the identity shift in these film characters relying on the works by Bakhtin and Bhabha in cultural theory. The aim is therefore to identify and describe conflicts in this cultural space that is characterised by change and fluidity.
\end{abstract}

Keywords: German film, cultural theory, identity formation, process of decentering identities

Resumo: neste artigo, apresentamos uma análise dos processos de diálogo e conflito cultural que influenciam a formação e o deslocamento de identidade das personagens no filme Bagdá Café. O objetivo principal deste trabalho é analisar o movimento identitário das personagens à luz das teorias culturais de Bakthin e Bhabha. Para tanto, buscamos identificar e descrever os conflitos de cunho cultural neste espaço, caracterizado pela mudança e fluidez.

Palavras-chaves: Filme alemão - Teorias culturais - Movimento identitário - Processo de deslocamento

1 Mestre em Tradução pela UFSC e doutoranda na Universidade Federal de Paraná. Email: eroschel@yahoo.com.

${ }^{2}$ Mestre em Letras/Alemão como língua estrangeira, Professora na Universidade Tecnológica Federal do Paraná. Email: franziska.lorke@gmail.com.

${ }^{3}$ Doutor em Letras/Alemão, Professor da Universidade Federal do Paraná. Email: henrijan@uol.com.br. 
Roschel Nunes/Lorke / Janzen. - Diálogo e conflito

Se eu mesmo sou um ser acabado e se o acontecimento é algo acabado, não posso nem viver nem agir: para viver, devo estar inacabado, aberto para mim mesmo - pelo menos no que constitui o essencial da minha vida -, devo ser para mim mesmo um valor ainda por-vir, devo não coincidir com a minha própria atualidade.

(BAKHTIN 1997: 33)

\section{Introdução}

Ao entrarmos em contato com outra língua, observamos alguns aspectos que transcendem questões linguístico-estruturais: são os encontros com outra cultura que geram deslizamentos culturais/identitários e que, entendemos, implicam novas orientações interculturais.

Diante dessas inquietações, pretendemos analisar o filme Bagdá Café e seus personagens como forma de exemplificar tais movimentos identitários. Os encontros e desencontros dos personagens tematizados no filme geram esses movimentos, que serão analisados com base na concepção de linguagem e cultura dos teóricos BAKHTIN (1997) e BHABHA (2010).

Bagdá Café (Out of Rosenheim), lançado em 1987, sob a direção de Percy Adlon, foi uma coprodução da Alemanha e dos Estados Unidos. Essa obra retrata o encontro de duas mulheres: uma turista bávara nos Estados Unidos e uma proprietária de posto de gasolina num lugar deserto. Depois de brigar com seu marido e abandoná-lo na estrada, a turista alemã Jasmin (Marianne Sägebrecht) caminha pelo deserto do Arizona até chegar ao posto-motel Bagdá Café. Brenda (CCH Pounder), dona do estabelecimento, que acabou de colocar o marido para fora de casa, recebe Jasmin com desconfiança e até mesmo aspereza. Jasmin, aos poucos, vai conquistando a simpatia dos clientes e hóspedes do motel, provocando mudanças não só na vida das pessoas do local como também na sua. Essas personagens, bem como seus conflitos e seus estranhamentos, serão objeto de nossa análise. 


\section{Roschel Nunes/ Lorke / Janzen. - Diálogo e conflito}

$\mathrm{Na}$ primeira parte do trabalho, discutiremos os principais conceitos de BAKHTIN (1997) е BНАВНА (2010) referentes ao encontro entre culturas e identidades. Os autores escolhidos partem de uma perspectiva sociocultural. Para ambos, são marcantes os conceitos de alteridade e hibridismo - aspectos que serão imprescindíveis para a análise do movimento identitário dos personagens da obra cinematográfica, o qual é ampliado para um contexto histórico e social maior, que redefine os personagens, influenciados pela história dos seus lugares. Na etapa seguinte deste trabalho, aplicaremos os conceitos dos referidos teóricos no estudo de algumas cenas do filme. Como a arte retrata a vida, tal análise contribui para a compreensão desses tipos de encontros e conflitos também em outros discursos socioculturais. Feitas as primeiras considerações, apresentaremos a seguir alguns importantes conceitos das obras de Bakhtin e Bhabha.

\section{Identidade e universo cultural}

A linguagem se constrói no coletivo - afinal, construímos nossos significados a partir do outro, que está sempre presente. E é pelos olhos de outro que o "eu" se enxerga. Em contato com o outro, regressamos a nós mesmos e procuramos em nossa consciência "um fundo que lhe seja transcendente", "um ponto de apoio" para dialogar em sociedade (BAKHTIN 1997: 38).

Tais conceitos se inserem no debate sobre a formação de identidades, trazendo novas perspectivas para os estudos culturais e quebrando antigos paradigmas e "grandes narrativas” (BHABHA 2010: 25). Nesse contexto, as fronteiras são repensadas, e a fixidez pré-dada é posta em xeque. Na verdade, estamos em um processo constante de negociação e dissolução do sujeito (BHABHA 2010: 25-27).

Esse processo marca movimentos identitários que não seguem uma sequência determinada, sendo impossível detectar fases isoladas que marcam o todo. Nessa mesma linha, BAKHTIN (1997: 47) assinala: 


\section{Roschel Nunes/ Lorke / Janzen. - Diálogo e conflito}

Os processos que nos levam à identificação com o outro, a completá-lo e a acabá-lo, não se situam necessariamente numa sucessão cronológica e apenas estamos procurando salientar a distinção de sentido que diferencia essas operações, estreitamente entrelaçadas na nossa vivência do outro.

$\mathrm{Na}$ análise proposta, apresentaremos sujeitos dissolúveis, representados pelas personagens Brenda e Jasmin, que, apesar de marcadas por "grandes narrativas" e padrões fixos de discursos absolutos, descobrem-se no outro e avançam para si mesmas. BAKHTIN (1997: 369) salienta que "a cultura alheia só se revela em sua completude e em sua profundidade aos olhos de outra cultura". O ponto de contato entre ambas as culturas estabelece um diálogo entre tais personagens. É nesse entremeio que o indivíduo se desloca, saindo do seu quadro relativista e percebendo-se a partir do outro.

\subsection{Fases de deslocamento do herói em uma perspectiva bakhtiniana}

Para BAKHTIN e seu círculo (1997), a partir da gama heterogênea de elementos linguísticos e culturais, os sujeitos realizam deslocamentos ao entrar em contato com o outro. A alteridade, neste mundo, é a condição de identidade. Estamos marcados pelo discurso do outro:

O locutor não é um Adão, e por isso o objeto de seu discurso se torna, inevitavelmente, o ponto onde se encontram as opiniões de interlocutores imediatos (numa conversa ou numa discussão acerca de qualquer acontecimento da vida cotidiana) ou então as visões do mundo, as tendências, as teorias, etc. (na esfera da comunicação cultural) (BAKHTIN 1997: 320).

Com base nos conceitos presentes nas obras Estética da criação literária (BAKHTIN 1997) e Questões de literatura e estética (a teoria do romance) (BAKHTIN 2002), apresentaremos três etapas de encontros culturais: ${ }^{4}$ duplicação, exotopia e acabamento do outro. A exotopia

\footnotetext{
${ }^{4}$ A definição das etapas foi realizada com base no trabalho de JANZEN (2005). Não estamos aqui propondo que essas fases estejam sempre presentes em todos os encontros culturais, mas sim que exista a possibilidade de serem concretizadas.
}

Pandaemonium, São Paulo, v. 16, n. 21, Jun/2013, p. 111-127 www.fflch.usp.br/dlm/alemao/pandaemoniumgermanicum 


\section{Roschel Nunes/ Lorke / Janzen. - Diálogo e conflito}

(a visão externa; de fora), a duplicação do outro (por meio da duplicação de discursos e da formação de estereótipos) e o acabamento do outro e de outra cultura são fases abordadas pelo autor com base no gênero romance e no papel do herói. Além dessas fases, BAKHTIN explora o conceito da construção híbrida, em que dois eixos de valores, duas vozes se encontram. Esse encontro de vozes diferentes acontece marcado por tais etapas e leva à hibridização da identidade do sujeito.

Os deslocamentos do indivíduo situam-se no universo cultural, descrito por Bakhtin como "um grande e infinito diálogo" (FARACO 2009: 42). A todo momento, pelo diálogo de diferentes vozes, construímos o nosso meio e as nossas narrativas. No sentido amplo do termo, o diálogo é como uma luta de vozes sociais, na qual atuam forças centrípetas e centrífugas (FARACO 2009: 71).

A visão de cultura, nessa perspectiva, não é homogênea, mas sim carregada de pontos de vista contraditórios e conflitantes, em que forças discursivas se contrapõem. Em um processo de união e descentralização, as forças centrífugas e centrípetas atuam no movimento social, no qual as mais diferentes vozes sociais se manifestam (BAKHTIN 1988: 82). Essas forças atuam em sentidos opostos: a primeira parte do centro para a periferia, a segunda se dirige ao centro. Isso significa que as forças centrípetas tentarão controlar a heterogeneidade discursiva ao buscar criar uma verdade absoluta. Em um movimento contrário, a força centrífuga tende a ampliar as visões de mundo, provocando o diálogo (BAKHTIN 1988: 53). Nesse contexto, repetimos discursos e, ao mesmo tempo, podemos replicá-los, promovendo o encontro de opiniões contraditórias. O indivíduo produz texto e o faz no âmbito da dinâmica histórica da comunicação (BAKHTIN 1988: 42), num duplo movimento: como réplica ao já-dito (BAKHTIN 1988: 32).

O diálogo é marcado pela plurivalência social dos signos, que possibilita a existência de muitas verdades, as quais podem ser interpretadas com base no próprio contexto social e cultural (FARACO 2009: 52). Assim, criamos os sentidos e elaboramos o enunciado considerando os discursos de outros, em maior ou menor grau, acrescentando "nossa tonalidade valorativa e expressividade", como se o enunciado fosse "uma arena, na qual atuam diversas vozes" (JANZEN 2005: 56). Ainda assim, nessa arena, podemos correr o 


\section{Roschel Nunes/ Lorke / Janzen. - Diálogo e conflito}

risco de negar a presença do outro partindo de uma única perspectiva, baseados em uma visão estereotipada fundada em um conjunto de experiências repetidas por determinado grupo, em um processo de duplicação do discurso dominante ${ }^{5}$.

Apesar dessas forças e das vozes que insistem em fixar sentidos, há o contradiscurso, a voz que questiona. Afinal "encontramo-nos no momento de trânsito em que espaço e tempo se cruzam para produzir figuras complexas de diferença e identidade [...]" (ВНАВНА 2010: 19).

\subsection{A perspectiva pós-colonial e a noção de hibridismo na teoria de Bhabha}

Assim como BAKHTIN, BHABHA levanta questões sobre o movimento identitário nessa complexa arena de vozes. De acordo com Homi BHABHA (2010), crítico pós-colonial indobritânico, vivemos um "momento híbrido de mudança política", uma vez que o "valor transformacional da mudança reside na rearticulação, ou tradução, de elementos que não são nem o um [...] nem o outro [...] mas algo a mais, que contesta os termos e territórios de ambos" (BHABHA 2010: 55).

Apoiado na perspectiva epistemológica bakhtiniana (principalmente na visão de hibridismo), BHABHA (2010) aponta para novos paradigmas referentes aos temas culturais da atualidade. Em seu trabalho "O local da cultura" (2010), o autor discute as grandes narrativas e seus efeitos na construção do sujeito. Como indivíduo marcado pela própria experiência de hibridização e deslocamento cultural, em sua obra BHABHA tece reflexões sobre o local deslizante da cultura, desestabilizado e sem significados fixos.

BHABHA (2010) mostra como o colonialismo está presente nas histórias e culturas até o presente e analisa por meio da linguagem (por exemplo, na literatura) os processos de negociação de significados culturais entre o colonizado e o colonizador. São esses

\footnotetext{
5 JANZEN (2005: 65) comenta sobre "o (aparente) diálogo cultural que não concebe efetivamente uma alteridade cultural (presença e voz do outro que me constituem) [e que] corre o risco de ser esvaziado numa duplicação de uma voz social (cultural)".
}

Pandaemonium, São Paulo, v. 16, n. 21, Jun/2013, p. 111-127 www.fflch.usp.br/dlm/alemao/pandaemoniumgermanicum 
Roschel Nunes/Lorke / Janzen. - Diálogo e conflito

processos que refletem momentos transicionais, num espaço de questionamento acerca da relação entre colonizado e colonizador na formação de outra identidade. Assim sendo, um depende do outro durante o processo de identificação. O colonizado dialoga com duas vozes discursivas: a voz do colonizador e a voz que personifica a nova realidade póscolonial. Ao mesmo tempo, o colonizador se sente ameaçado ${ }^{6}$ pela voz do colonizado, que pode refletir uma imagem diferente da autoimagem do primeiro. Isso pode acontecer mediante a possibilidade de criar praticidades culturais diferentes e de usar processos de translação cultural para transformar o original repetidamente ${ }^{7}$.

São esses processos de negociação de significados culturais que nos levam a um território híbrido. Nesse espaço, surgem novas posições, capazes de influenciar não somente as histórias nacionais, a política e as estruturas de poder, mas também a formação identitária $^{8}$ do sujeito. Esse é o entre-lugar, entendido por BHABHA (2010: 298) como um "espaço internacional de realidades históricas descontínuas" no qual os sujeitos se abrem, retraçam fronteiras, questionam limites e "diferenças". É o encontro entre as culturas, o ato de negociar novos sentidos, entendendo que esses conceitos são construídos historicamente, como se evidencia no caso dos personagens de Bagdá Café, influenciados por suas bagagens histórico-culturais. Nesse sentido, considerando os aspectos acima apontados, a noção de hibridismo, vinculada ao conceito de entre-lugar, fornece uma base teórica relevante para a análise dos movimentos e deslocamentos realizados pelos personagens durante o filme.

${ }^{6}$ David HUDDART propõe que "colonial doubling is something that troubles the self-image of the colonizer" e que o colonizado não é simplesmente dominado, mas que existe um espaço para negociação e transformação na relação entre o colonizado e o colonizador: "[...] the meaning of culture is not simply imposed by the colonizer. The colonizer's cultural meanings are open to transformation by colonized population [...]. When colonizer and colonized come together, there is an element of negotiation." (2006: 2).

${ }^{7}$ BHABHA refere à estes processos como praticidades que criam o hibridismo na esfera da cultura: "Now the notion of hybridity comes from two prior descriptions I've given of the genealogy of difference and the idea of translation, because if [...] the act of cultural translation [...] denies the essentialism of a prior given original or originary culture, then we see that all forms of culture are continually in a process of hybridity." (1990: 211).

${ }^{8}$ BHABHA entende a formação da identidade como um processo de identificação por intermédio do outro. Porém, o sujeito é sempre ambivalente por causa do outro em si mesmo. (1990: 211).

Pandaemonium, São Paulo, v. 16, n. 21, Jun/2013, p. 111-127 www.fflch.usp.br/dlm/alemao/pandaemoniumgermanicum 
Roschel Nunes/Lorke / Janzen. - Diálogo e conflito

\subsection{Pontos de encontro entre os autores}

O hibridismo é um conceito importante tanto na obra de BHABHA quanto na de BAKHTIN que elabora, como citamos anteriormente, outros conceitos relevantes para a nossa discussão, como o plurilinguismo, a alteridade e sua natureza dialógica. Para BHABHA (2010: 51), o hibridismo marca o processo de negociação cultural cujos confrontos promovem a negação de uma identidade pura. BAKHTIN (1997: 299), por sua vez, entende o mundo da cultura como um grande e infinito diálogo, no qual diferentes vozes se encontram, possibilitando a construção híbrida do ser.

Nesse contexto sociocultural, desenvolvem-se processos que são produzidos na “articulação das diferenças culturais”. BHABHA (2010: 20) usa o termo "entre-lugares” para designar esses processos, os quais fornecem a base para a formação do sujeito, em um jogo de colaboração e contestação. Segundo o autor, é esse conjunto de movimentos que permite a passagem entre identificações fixas e que, além disso, promove o hibridismo cultural, processo que "acolhe a diferença sem uma hierarquia suposta ou imposta". (BHABHA 2010: 22).

Como o filme mostra por meio de discussões e divergências dos personagens, os possíveis conflitos nesse meio podem ser produtivos para os sistemas culturais sem fronteiras ou significados fixos. Em tal espaço, "nenhuma cultura é jamais unitária em si mesma" (Bнавна 2010: 65). Pelo contrário, move-se em um "espaço contraditório e ambivalente, no qual símbolos ou significados não têm unidade ou fixidez" e em que a tradução e a negociação entre culturas possibilitam a criação do "entre-lugar" (BHABHA 2010: 64-69).

Da mesma forma, partindo da visão dialógica de BAKHTIN (1997: 335), pode-se afirmar que "a consciência individual se constrói na interação" (FARACO 2009: 42). Afinal:

O ato humano é um texto potencial e não pode ser compreendido (na qualidade de ato humano distinto da ação física) fora do contexto dialógico de seu tempo (em que figura como réplica, posição de sentido, sistema de motivação) (BAKHTIN 1997: $335)$. 
Roschel Nunes/Lorke / Janzen. - Diálogo e conflito

BAKHTIN (1997: 44) situa o outro na sua posição única, "fora de mim”, mas presente na construção da identidade do "eu". A posição do sujeito ou do "eu" é única, com perspectivas por vezes inacessíveis ao "outro" 9 . O outro possibilita a troca, a interação e a construção da própria identidade do sujeito. Carregamos nosso arsenal de vozes e nosso histórico para a interação, no entanto somos constituídos com base no outro.

Daí a importância de considerar o universo cultural. Cada posição que o sujeito ocupa é sempre "um processo de tradução e transferência de sentido" (BHABHA 2010: 53), em que o sujeito forma sua identidade a partir do outro. É esse sujeito complexo, movido por forças centrípetas (centralizadoras de discursos) e centrífugas (que desunificam discursos unitários e homogêneos), ativo na presença do outro, marcado pelo hibridismo construído no "entre-lugar" de culturas, que analisaremos, a seguir, em algumas cenas do filme Bagdá Café.

\section{Momentos do filme}

Considerando os conceitos de Bakhtin que caracterizam o movimento e o deslocamento do sujeito no universo social e cultural, apresentaremos uma análise das cenas escolhidas como ilustração para discussão teórica. Com base nos exemplos, serão trabalhados os elementos que constituem as "fases" do processo de diálogo entre culturas e de formação identitária. As "fases" e os conceitos expostos não seguem uma sequência, nem acontecem isoladamente, mas são destacados para facilitar a observação e a análise. Como já mencionamos, o processo ocorre sem fixidez temporal ou espacial.

\footnotetext{
9 “Quando contemplo um homem situado fora de mim e à minha frente, nossos horizontes concretos, tais como são efetivamente vividos por nós dois, não coincidem. Por mais perto de mim que possa estar esse outro, sempre verei e saberei algo que ele próprio, na posição que ocupa, e que o situa fora de mim e à minha frente, não pode ver: as partes de seu corpo inacessíveis ao seu próprio olhar [...].” (BAKHTIN 1997: 44).
} 


\section{Roschel Nunes/ Lorke / Janzen. - Diálogo e conflito}

Em sua obra Estética da criação verbal, BAKHTIN (1997) parte do estudo literário, vinculando a criação de heróis e a relação entre autor e herói na literatura a questões culturais e processos de exotopia temporal, espacial e cultural. Para caracterizar o processo de exotopia - importante conceito para nossa análise -, o autor literário utiliza a imagem de pontos de apoio que flutuarão em um solo movediço, ou seja, esses pontos de apoio serão aleatórios e dependerão dos outros personagens com os quais se depara o "herói” (Cf. BAKHTIN 1997: 38s). A exotopia é, na verdade, um instrumento de compreensão de outra cultura. $\mathrm{O}$ olhar do outro cria um sentido alheio que permite o diálogo entre os sujeitos e o abandono de uma postura unívoca e fechada.

Como BAKHTIN (1997: 136) afirma, "na vida, participo do cotidiano, dos costumes, da nação, da humanidade, do mundo terreno - em toda parte, vivo aí os valores no outro e para o outro [...]". Em conjunto com o outro, produzimos e transferimos sentidos. A partir do outro, somos ativos: "no coro, meu canto não se dirige a mim, sou ativo só a respeito do outro [...]". (BAKHTIN 1997: 136).

No filme Bagdá Café, o olhar do outro e os conflitos entre mundos e significados são abordados intensivamente por meio do encontro de duas personagens de diferentes contextos culturais, vivenciando momentos semelhantes da vida. Após a separação conjugal, as mulheres tentam recomeçar ou levar a vida adiante. Em meio à crise emocional, elas se encontram no Bagdá Café. O cenário é peculiar: um local isolado, como se estivesse localizado às margens da sociedade, apenas usado como ponto de parada por alguns viajantes, caminhoneiros e pessoas sem direção, como a própria Jasmin, que abandona o marido na estrada, levando consigo apenas a mala de viagem.

Em sua bagagem, Jasmin traz não apenas símbolos e objetos de sua terra natal, mas também um histórico pessoal influenciado pela história cultural de sua comunidade bávara - a Baviera, um estado no sul da Alemanha, possui uma forte imagem internacional "formada" por seus símbolos, como trajes, festas, dialeto, entre outros.

Como personagem fixada nos valores unívocos de sua comunidade, Jasmin percebe o Café como caótico e, com base em suas referências culturais, surpreende-se com a falta de organização. A própria Brenda - mulher negra, dona do estabelecimento - causa certo 


\section{Roschel Nunes/ Lorke / Janzen. - Diálogo e conflito}

estranhamento a Jasmin. Movida por uma visão estereotipada, difundida em discursos e narrativas colonizadoras europeias sobre os negros, Jasmin se imagina sendo devorada por Brenda e seu grupo (19 min).

Tendemos a repetir "grandes narrativas" e a criar estereótipos, como forma de fixar sentidos. O estereótipo, como BНABHA (2010: 117) salienta, é "uma simplificação porque é uma forma presa, fixa, de representação", que parte de um discurso conhecido, como "algo que deve ser ansiosamente repetido" (BНABHA 2010: 105). Aliado ao estereótipo, o discurso colonial se revela como "um aparato de poder", mediante o qual o colonizado é apresentado como "uma população de tipos degenerados com base na origem racial de modo a justificar a conquista e estabelecer sistemas de administração e instrução” (BHABHA 2010: 111).

É com essa visão que Jasmin inicia sua ação de limpeza e organização, ainda motivada pelo estranhamento, que "move-se sobre nós furtivamente como nossa própria sombra” (BHABHA 2010: 29). Nesse momento, notamos como os problemas de interação surgem nas "fronteiras significatórias", ou seja, quando se contesta significados e valores, e quando se parte de costumes culturais pré-dados em um enquadramento fixo de uma “identidade coletiva única” (BHABHA 2010: 63). Jasmin não se conforma com o "caos americano" e decide trazer a "organização alemã” para o escritório da Brenda em um processo de duplicação dos discursos que ouviu a vida inteira. Após essa atitude, dá-se o conflito entre as personagens e suas visões de mundo, quando Brenda percebe as mudanças feitas no seu escritório (45 min):

Brenda: $\quad$ Era meu escritório, certo? Meu escritório. Dê uma olhada! Isto deveria ser um escritório. Chama isso de escritório? Está vazio! Como alguém pode trabalhar aqui? Será que pode me dizer, Senhora...?

Jasmin: $\quad$ Sra. Munchgstettner.

Brenda: $\quad$ Venha cá, Senhora. Seja lá qual for seu nome! Quem lhe deu permissão, afinal? Quem disse que era da sua conta? O que tem a ver com isso? Onde está tudo? O que fez com tudo? No lixo? Fantástico! É simplesmente fantástico. Agora preste atenção. Traga tudo aqui de volta. Tudo! E ponha de volta onde estava. Tudinho exatamente como estava.

[Um tiro dispara da arma que Brenda está carregando.] 


\section{Roschel Nunes/Lorke / Janzen. - Diálogo e conflito}

No decorrer da narrativa, entretanto, percebe-se um deslocamento da personagem Brenda ao adotar alguns comportamentos característicos de Jasmin. Mais tarde, o escritório passa a ser mais bem organizado por ela. Até os clientes comentam. Nesse âmbito, pode-se falar em um deslocamento produtivo, pois ambas iniciam um processo de reflexão e mudança da própria identidade a partir do outro. Brenda se desloca, duplicando o discurso de organização e limpeza que Jasmin iniciou.

Em várias cenas do filme, dois eixos de valores entram em conflito e dialogam. Por exemplo, no momento em que Jasmin e Phyllis (filha adolescente de Brenda, a proprietária do Café) provam roupas típicas da Baviera e experimentam contrastes da pele: nessa cena, uma se enxerga através da outra (54 min):

\begin{tabular}{|c|c|}
\hline Phyllis: & O que é isto? \\
\hline Jasmin: & Jardineira de couro. \\
\hline Phyllis: & Jardineira de couro? \\
\hline Jasmin: & Jardineira de couro. \\
\hline \multicolumn{2}{|c|}{ [Phyllis prova a jardineira.] } \\
\hline Jasmin: & Tem lugar para dois! \\
\hline \multicolumn{2}{|c|}{ [Jasmin olha para a pele da mão da Phyllis.] } \\
\hline Phyllis: & O que há? \\
\hline Jasmin: & São tão luminosas por dentro. \\
\hline Phyllis: & Bonitas, não? Também gosto. \\
\hline
\end{tabular}

Lentamente, Jasmin começa a mudar a aparência, solta o cabelo e usa roupa mais leve, em um processo de liberação dos discursos rígidos e de toda fixidez que a acompanhava até então. A troca e o diálogo com o outro permitiram a Jasmin ampliar seu campo de visão e buscar a si mesma com base em sua história e identidade. Nesse processo, nossa heroína precisa do outro, pois sua visão não se completa sozinha, conforme descreve BAKHTIN (1997: 57): “Ao virar a cabeça em todas as direções, obtenho uma visão do espaço que me cerca de todos os lados e em cujo centro eu me situo, mas não verei a mim mesmo cercado por esse espaço". 


\section{Roschel Nunes/ Lorke / Janzen. - Diálogo e conflito}

Nessa busca, Jasmin se movimenta, deslocando-se de seu ângulo fixo, abrindo espaço para o encontro consigo a partir do outro, sem se estagnar. Esse caminho é instável e constante:

Minha relação com o objeto situado em meu horizonte nunca é uma relação acabada, mas uma relação pré-dada, pois o acontecimento existencial em seu todo é um acontecimento aberto; minha situação se modifica a todo momento, eu não posso demorar ou ficar em repouso (BAKHTIN, 1997: 113).

Para espelhar a força desse movimento e as transformações das personagens, o filme utiliza a arte (pintura, música, dança e mágica). É assim que, ao ver-se representada nos quadros pintados por um admirador, Jasmin descobre "outra" dentro dela mesma, uma mulher bonita e desejada. Posando de maneira cada vez mais ousada e vendo-se assim retratada, Jasmin entra em um processo de deslocamento da identidade, despindo-se lentamente de seus trajes tradicionais até chegar à nudez, que reflete o processo de libertação. Ao despirse, a personagem se desfaz também de seus símbolos culturais.

Brenda, por sua vez, inicia um processo de deslocamento e de exotopia com relação a Jasmin. Primeiramente, com a própria organização do escritório e do local; depois, com a participação no show de mágicas, culminando com a valorização do talento musical de seu filho.

A música é um importante aspecto do filme, usada como ponte de comunicação além das fronteiras. $\mathrm{O}$ filho de Brenda, incompreendido pela maioria das pessoas do local, encontra em Jasmin alguém de "seu mundo", que valoriza sua música clássica. A identificação com Jasmin é evidente na cena ao piano, quando a forasteira incentiva o rapaz a tocar. Com poucas palavras, os personagens se entendem e se encontram por meio da música. Pela primeira vez, depois de muito tempo, o garoto pergunta sobre a origem de Jasmin. Ao ouvir a resposta "Baviera", ele se emociona e, admirando o quadro de Bach, afirma: "Eu sabia".

Notamos aqui o poder da música e da arte transpondo fronteiras e barreiras comunicativas. BAKHTIN (1997: 135) observa a arte como representação da alma, para além de fronteiras ou "mundos": 
Roschel Nunes/Lorke / Janzen. - Diálogo e conflito

$\mathrm{Na}$ arte, o mundo das coisas onde vive e evolui a alma do herói é esteticamente significante a título de ambiente dessa alma. Na arte, o mundo não é o horizonte do espírito atuante e sim o ambiente da alma que se retirou ou está se retirando. A relação do mundo com a alma (relação esteticamente significante e combinação entre o mundo e a alma) é análoga à relação da imagem visual do mundo com o corpo: o mundo não se situa defronte da alma, mas a rodeia e a engloba, combinando-se com suas fronteiras; o dado do mundo entra em combinação com o dado da alma.

Em vários momentos do filme, os processos de exotopia e acabamento ficam evidentes, quando o sujeito se vê por intermédio do outro, na tentativa de ser completo e compreendido pelo outro. No processo de exotopia, o olhar de fora permite enxergar por outro ângulo, diferentemente da perspectiva desse sujeito. Desse lugar, que ele é o único a ocupar, desenvolve-se o excedente de visão, que permite perceber fatos inacessíveis ao outro (JANZEN 2005: 61). É assim que esses fatos completam o "outro" com elementos que ele não pode enxergar.

Nas palavras de BAKHTIN (1997: 35), a exotopia "vai subtrair o herói à solidariedade em comum e à responsabilidade coletiva e vai engendrá-lo, enquanto novo homem, num novo plano da existência, onde ele não poderia nascer por própria conta e pelas próprias forças". A exotopia permite o afastamento e "a compreensão que participa no acabamento do acontecimento da vida do herói [...]” (BAKHTIN 1997: 36). Trata-se, portanto, de um processo de troca e enriquecimento, em que há busca pelo "eu" considerando-se o que o outro oferece. Tal processo é incomensurável, contingente e contínuo. Estamos o tempo todo reinventando novos "eus" a partir do "outro".

Nesse processo de busca, Jasmin aprendeu muito sobre os valores de Brenda, e viceversa. As duas se enxergam com o olhar do outro, completando-se a partir do outro. Elas experimentam novos lugares e horizontes aceitando o olhar do outro como algo que pode completá-las ou enriquecer suas experiências.

É assim que, ao voltar para sua "casa", para seu país, Jasmin já não se encontra e enxerga sua própria vida com outros olhos. Enquanto isso, no Café de Brenda, o café passa a ser feito como na Alemanha, e as pessoas sentem falta de Jasmin e de suas "mágicas". 


\section{Roschel Nunes/ Lorke / Janzen. - Diálogo e conflito}

No início do filme, Jasmin percebe durante o caminho percorrido até o café a imagem de dois sóis no deserto, como dois caminhos abertos à sua frente. Entre os caminhos traçados, entre estranhamentos, deslocamentos e acabamentos, ela se revela como sujeito cindido, duplo e ambivalente em um processo constante de diálogo com o outro e de encontro consigo mesma. Por fim, ela escolhe seu caminho e decide voltar ao Café, onde vivenciou a experiência exotópica de descobrir-se em processos infinitos de conflitos e acabamentos.

\section{Conclusão}

Por meio da análise do filme Bagdá Café, observamos que a identidade cultural é algo processual, construído pelo encontro com diferentes sujeitos. Esse encontro ou diálogo pode resultar em conflitos criativos, pois contribuem para que a própria percepção e a visão de mundo se reconstruam. Nessa experiência, o indivíduo se percebe e se vê por intermédio do outro. Em outras palavras, os conflitos que surgem são inerentes ao processo de construção do sujeito; nem sempre é possível evitá-los e fugir dessa dinâmica, sendo, por vezes, necessário o estranhamento para enxergar-se pelos olhos do outro.

Convém frisar que o conceito de hibridismo abordado não pretende solucionar os conflitos entre culturas, os quais fazem parte de um processo ideológico de constante ressignificação do sujeito. Em nosso momento histórico - em que fatores como a globalização cultural, os "entre-lugares", no dizer de BНАВНА, e o presente provisório em transição marcam a descentralização do indivíduo -, é justamente em razão desses conflitos que o sujeito se reinscreve em seu meio. Esse local de conflito é um espaço criativo, onde as diferentes identidades dialogam e se reinventam.

Além disso, nas cenas analisadas notamos que não existem momentos estanques; as fases descritas por BAKHTIN ocorrem sem uma sequência fixa, com movimentos não determinados previamente. Afinal, estamos sempre vivendo a contingência do momento. A exotopia, o acabamento e o deslocamento do sujeito são observados nesse diálogo e 


\section{Roschel Nunes/Lorke / Janzen. - Diálogo e conflito}

caracterizam os movimentos no universo cultural, em que identidades sociais se formam e se reformulam. Identidades envolvidas e constituídas a partir do outro. A importância da alteridade se revela diante dos valores que possuímos e que só são possíveis com relação ao outro. É o outro que dá à nossa vida um “peso de acontecimento particular":

Apenas o outro torna possível a alegria que sentirei ao encontrá-lo, ao estar com ele, o pesar que sentirei ao deixá-lo, a dor que sentirei ao perdê-lo; e é somente com ele que posso encontrar-me e somente dele que posso separar-me no espaço temporal. (BAKHTIN 1997: 121).

Além de nos certificarmos da importância do "outro", ao percebermos que somos constituídos por várias vozes e ao re-significarmos nossas histórias, temos a oportunidade de transformar e recriar a noção de pertencer a uma cultura e reavaliar nossas narrativas (Cf. BНАВHA 2010: 324), concedendo um novo significado para o espetáculo social:

O signo da história não consiste em uma essência de acontecimento em si, nem exclusivamente na consciência imediata de seus agentes e atores, mas na sua forma enquanto espetáculo - espetáculo que significa por causa do distanciamento e deslocamento entre o acontecimento e seus espectadores (BHABHA 2010: 335).

O processo de acabamento na obra literária e na arte reflete também o acabamento na vida. Trata-se de um processo de troca e enriquecimento, durante o qual há busca pelo "eu" a partir do que o outro oferece. Ao identificar-me com o outro e ver o mundo como ele o vê, posso completar meu horizonte e perceber o espaço que ocupo, já que sou capaz de usar o excedente de minha visão a partir do lugar onde estou (BAKHTIN 1997: 44-46).

Em um espaço de questionamentos acerca dos significados, do hibridismo, da nação imposta, da duplicação e do estranhamento em outros momentos e lugares de enunciação, refletimos sobre o ser em outros tempos e espaços com base em nossa bagagem de vozes e narrativas. Reflexões desse tipo contribuem para a percepção de nossa "comunidade imaginada", com matrizes ideológicas nacionais e tradições.

A ideia é permitir espaço para negociação entre identidades híbridas e, ao perceber um possível "racismo mal disfarçado" (BHABHA 2010: 345), estar em condições de analisar 
Roschel Nunes/Lorke / Janzen. - Diálogo e conflito

melhor a questão da formação do sujeito e o poder da tradução pós-colonial, reavaliando a tradição, os mitos e as "grandes narrativas" que conosco carregamos.

\section{Referências Bibliográficas}

BAGDA CAFÉ. Direção: Percy Adlon. 1987.

BAKTHIN, Mikhail. Estética da criação verbal. São Paulo: Martins Fontes, 1997.

Questões de literatura e estética (a teoria do romance). São Paulo: Hucitec, 1988.

BHABHA, Homi K. O local da cultura. Belo Horizonte: Editora UFMG, 2010.

BнAвHA, Homi K. The Third Space. Interview with Homi Bhabha. In: RUTHERFORD, Jonathan (ed.). Identity:Community, Culture, Difference. London: Lawrence + Wishhart, 1990, 207221.

FARACO, Carlos Alberto. Linguagem \& diálogo - as ideias linguísticas do círculo de Bakhtin. São Paulo: Parábola Editorial, 2009.

HudDART, David. Homi K. Bhabha. London and New York: Routledge, 2006.

JANZEN, Henrique. O Ateneu e Jakob von Gunten: um diálogo intercultural possível. Tese Doutorado em Língua e Literatura Alemã. São Paulo: USP, 2005.

Recebido em 10/03/2013

aprovado em 20/04/2013 